\title{
Heart Retransplantation
}

\author{
M. R. Johnson ${ }^{a}{ }^{*}$, K. D. Aaronson ${ }^{\text {b }}$, C. E. Canter ${ }^{\text {, }}$, \\ J. K. Kirklin ${ }^{\text {, D. M. Mancinie }}{ }^{\text {, M. R. Mehraf, }}$ \\ B. Radovancevicg, D. O. Taylor ${ }^{h}$ \\ and S. A. Webberi \\ aniversity of Wisconsin, Madison, WI \\ b University of Michigan, Ann Arbor, MI \\ 'St. Louis Children's Hospital, St. Louis, MO \\ 'University of Alabama at Birmingham, Birmingham, AL \\ e Columbia University College of Physicians and Surgeons, \\ New York, NY \\ ${ }^{\mathrm{f}}$ University of Maryland, Baltimore, MD \\ g Texas Heart Institute, Houston, TX \\ ${ }^{\mathrm{h}}$ Cleveland Clinic Foundation, Cleveland, $\mathrm{OH}$ \\ 'Children's Hospital of Pittsburgh, Pittsburgh, PA \\ * Corresponding author: Maryl R. Johnson, \\ mrj@medicine.wisc.edu
}

Retransplants comprise only a small minority (3-4\%) of heart transplants, however outcome following retransplantation is compromised. Risk factors for a poor outcome following retransplantation include retransplantation early ( $<\mathbf{6}$ months) after primary transplant, retransplantation for acute rejection or early allograft failure, and retransplantation in an earlier era. The incidence of rejection and infection is similar following primary transplant and retransplantation. The compromised outcomes and risk factors for a poor outcome are similar in adult and pediatric heart retransplantation. However, due to the short half-life of the transplanted heart, it is an expectation that patients transplanted in childhood may require retransplantation. Based on the data available and the opinion of the working group, indications for heart retransplantation are (i) chronic severe cardiac allograft vasculopathy with symptoms of ischemia or heart failure (should be considered) or asymptomatic moderate or severe left ventricular dysfunction (may be considered) or (ii) chronic graft dysfunction with symptoms of progressive heart failure in the absence of active rejection. Patients with graft failure due to acute rejection with hemodynamic compromise, especially $<6$ months post-transplant, are inappropriate candidates for retransplantation. In addition, guidelines established for primary transplant candidacy should be strictly followed.

Key words: Cardiac allograft vasculopathy, heart transplantation, retransplant

Received 26 January 2007, revised 25 May 2007 and accepted for publication 29 May 2007

\section{Introduction}

Retransplantation is the indication for heart transplantation in only a small minority of cases. Retransplanted recipients have compromised outcomes compared with first transplant recipients; therefore, with the donor shortage, the appropriate role of heart retransplantation should be assessed. A complete analysis of outcomes following retransplantation and risk factors for a poor outcome following retransplantation would help in the development of guidelines for retransplantation in heart transplant recipients. This was performed by the working group on Heart Retransplantation, which was convened as a part of a Consensus Conference on Retransplantation sponsored by the American Society of Transplantation, the American Society of Transplant Surgeons and the National Institute of Allergy and Infectious Diseases in Atlanta, Georgia, on March 7th and 8th, 2006. The working group developed recommendations, based on the data available and expert opinion, concerning heart retransplantation. Areas where further study is needed to better define the role of heart retransplantation were also delineated.

\section{Retransplantation in the Scientific Registry of Transplant Recipients (SRTR)}

From 2000 to 2005, 364 heart retransplants were reported to the SRTR, which accounted for $2.9 \%$ of all heart transplants (1). One-year, 3-year and 5-year unadjusted graft survival was lower in retransplants than in first transplants (82\% vs. $86 \%, 70 \%$ vs. $80 \%$ and $58 \%$ vs. $73 \%$, respectively, all $p<0.0001)$. At the end of 2005 , only $5.3 \%$ of all heart transplants registrations were candidates for retransplantation. However, when the percent of new heart registrations is evaluated by recipient age, since 1996 there has been a progressive increase in registrations for retransplantation in the 0-17-year-old age group, with a similar trend seen more recently for 18-49-year olds (1) (Figure 1).

\section{Multicenter and Single Center Data Concerning Heart Retransplantation}

In an early study of retransplantation at 13 centers in the United States, 1-year survival was only $60 \%$, but the incidence of rejection, infection, and cardiac allograft vasculopathy did not differ between retransplant and primary transplant recipients (2). Retransplantation of 'ideal candidates' (defined as patients with cardiac allograft 


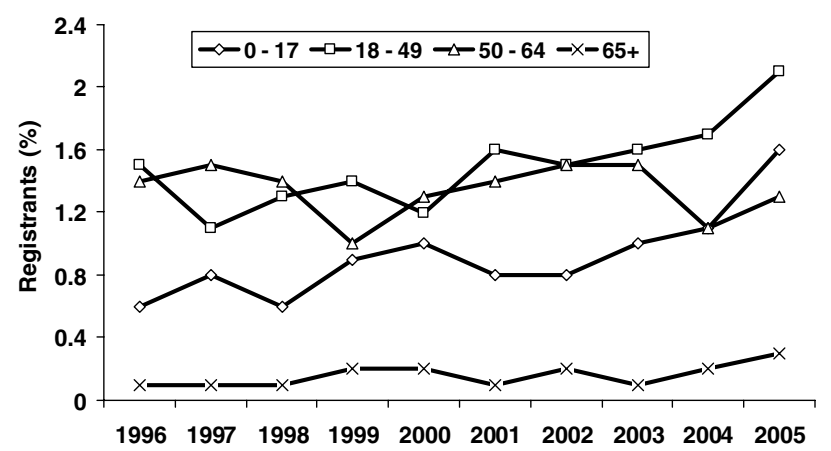

Figure 1: Percent of new heart registrations added to the United Network for Organ Sharing (UNOS) list for heart retransplantation by age, 1996-2005. (Organ Procurement and Transplant Network (OPTN) Analysis, February 2006. from Magee et al. Am J Transplant 2007; 7(Part 2): 1424-1433.)

vasculopathy as the indication for retransplantation, $>6$ months between transplants, a lack of preoperative mechanical assistance, and a second transplant occurring after 1985 ) yielded a 1-year survival of $74 \%$, which was still compromised compared with overall post-transplant survival.

In the International Society for Heart and Lung Transplantation (ISHLT) Registry, representing 56,609 patients transplanted between January 1982 and June 2003, 1125 retransplants were included, representing only $2 \%$ of total transplant recipients (3). As seen in Figure 2, survival following retransplantation was significantly compromised compared with that of patients transplanted for all other indications. Retransplantation was found to be a significant risk factor for mortality at 1, 3, 5 and 10 years following transplantation. In a further analysis of the Joint ISHLT/United Network for Organ Sharing (UNOS) Thoracic Registry, for 514 retransplant recipients the most common indications for retransplantation were cardiac allograft vas-

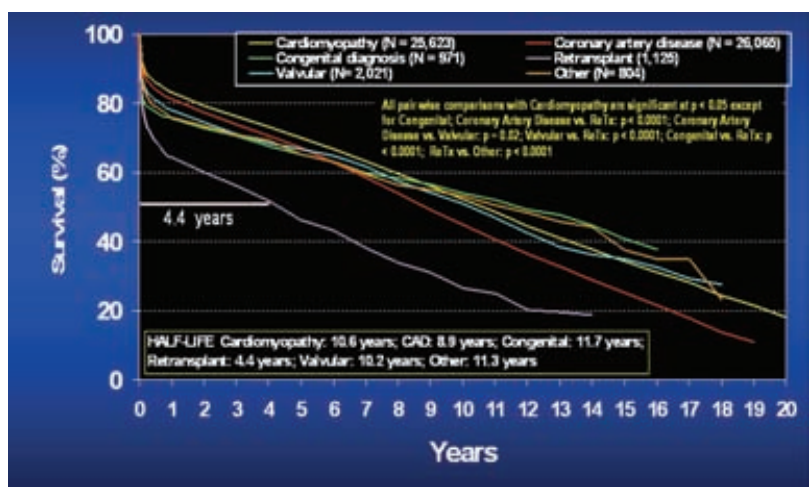

Figure 2: Survival following heart transplantation by indication for transplantation, 1/1982-6/2003, in the Registry of the International Society for Heart and Lung Transplantation.

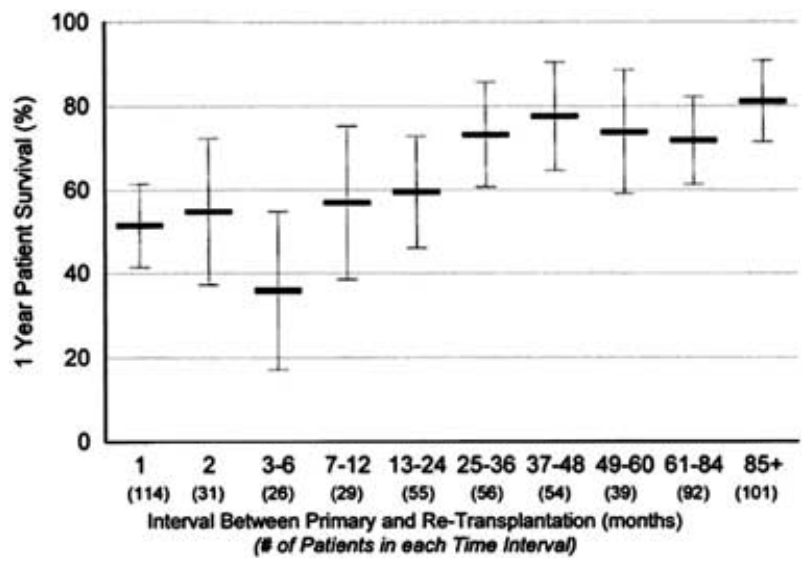

Figure 3: Patient survival following retransplantation stratified by inter-transplant interval in an analysis of the Joint International Society for Heart and Lung Transplantation and United Network for Organ Sharing Thoracic Registry, $\mathbf{n}=\mathbf{5 1 4}$. (Reproduced with permission, Transplantation 2000; 70(4):606612.)

culopathy (56\%) and primary nonspecific graft failure (18\%) (4). Nine percent of patients were retransplanted due to acute rejection and $3 \%$ due to hyperacute rejection. Survival for retransplant recipients was $65 \%, 59 \%$ and $55 \%$ at 1,2 and 3 years, respectively, all significantly lower than the survival for all heart transplant recipients in the database. Outcome following retransplantation was significantly affected by the time between transplants with an inter-transplant interval of 2 years or less resulting in a 1year survival less than $60 \%$. However, if the inter-transplant interval was greater than 2 years, 1-year survival increased to $75 \%$ - a figure much closer to the approximately $80 \%$ 1 -year survival of first heart transplants for the same period (Figure 3).

Radovancevic et al. reported on 106 retransplant recipients of 7290 heart transplants from January 1990 through 1999 included in the Cardiac Transplant Research Database (5). The primary indications for retransplantation were cardiac allograft vasculopathy $(37 \%)$, early graft failure $(32 \%)$, and acute cardiac rejection (14\%). Survival after retransplantation was inferior to that after primary transplantation with a survival of $56 \%$ at 1 year and $38 \%$ at 5 years. Risk factors for death after retransplantation included retransplantation for acute rejection or early graft failure and the use of a female donor. Survival following retransplantation for acute rejection was extremely low, with a $32 \% 1$-year survival and $8 \%$ 5-year survival (Figure 4). No significant differences in freedom from rejection or infection were seen in retransplant compared with primary transplant recipients, although there was a trend toward more infections in retransplant recipients. The interval between the first and second transplant again affected survival, with patients retransplanted in the first 6 months having the worst outcome (Figure 5). Survival was better in those retransplanted 


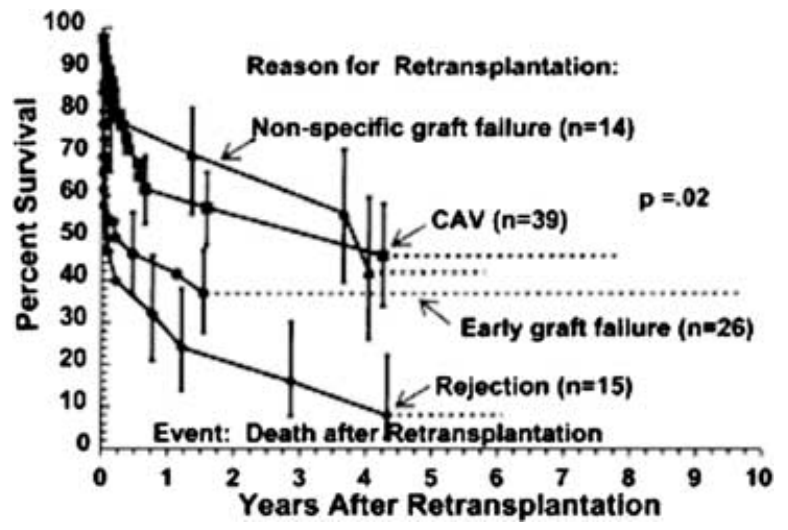

Figure 4: Outcome following retransplantation by indication in the Cardiac Transplant Research Database Retransplantation Study, 1990-1999, $\mathbf{n}=\mathbf{7 2 9 0}$. (Reproduced with permission, J Heart Lung Transplant 2003; 22(8):862-868.)

from 1996 to 1999 than in those retransplanted earlier. There was a trend toward decreased survival in patients aged greater than 60 when retransplanted compared with those retransplanted at a younger age, however, the difference was not significant. The investigators concluded that due to poor outcomes, retransplantation for acute rejection and early graft failure should generally not be considered. However, retransplantation for cardiac allograft vasculopathy was associated with good enough survival that it was felt appropriate in carefully selected recipients.

Table 1 summarizes data from selected series of adult heart retransplantation (6-10). In all cases the percent of transplants that were retransplants was low (2.3-8\%), the most common indication for retransplantation was cardiac allograft vasculopathy, and survival following retransplantation was compromised compared with that of primary transplant recipients. In another report from Columbia the au-

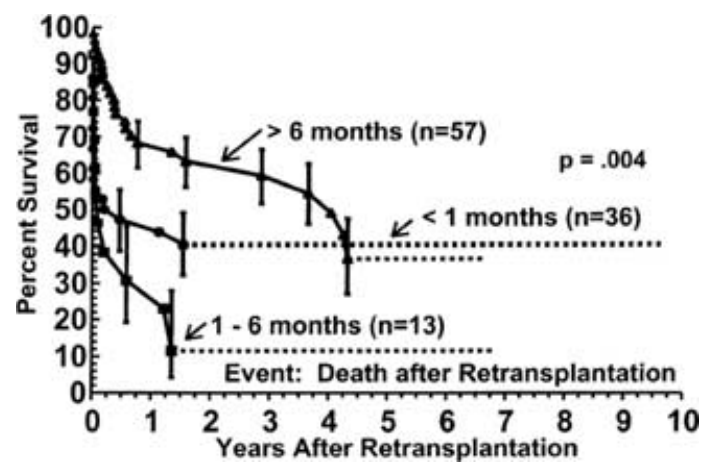

Figure 5: The interval between primary transplant and retransplantation significantly affected survival in retransplants reported to the Cardiac Transplant Research Database. (Reproduced with permission, J Heart Lung Transplant 2003; 22(8):862868.) thors reported that since 1993, when selection criteria for retransplantation excluded retransplantation for primary allograft failure and intractable acute rejection occurring less than 6 months after transplantation, 1, 2 and 4 year survival following retransplantation was $94 \%, 94 \%$ and $94 \%$, respectively (11). This indeed suggests that if appropriate candidates are selected for retransplantation, outcomes can equal those following primary transplantation.

As the rates of rejection, infection, and cardiac allograft vasculopathy are similar in primary transplants and retransplant recipients, the question arises as to why outcomes are compromised following retransplantation. It should be remembered that the rates of rejection, infection, and allograft vasculopathy reflect what happened in the survivors. As seen in Figure 2, the survival curves diverge early following transplant and then are nearly parallel. This suggests that the differences in survival likely represent perioperative and early postoperative events such as primary graft failure, multi-organ failure, bleeding, etc., although this hasn't been closely analyzed.

\section{Pediatric Retransplantation}

In considering retransplantation in children, several factors suggest that special considerations are appropriate. First, many, if not most, pediatric recipients are not involved in the decision to undergo primary heart transplant. In addition, due to the short half-life of a transplanted heart (17.5 years for recipients age $1-10$ and 13.7 years for recipients 11-17 years) (12) there is an expectation that retransplantation (and, at times a third transplant) may be required in children. An additional complicating factor is that children transition to follow-up by an adult heart transplant program as they reach adult age, and adult programs often have a less aggressive stance on retransplantation. Thus, it is important for all involved to thoroughly consider the role of retransplantation in the pediatric population.

An analysis of UNOS data concerning pediatric heart transplantation from 1987-2004 reported 219 retransplants among 4227 total transplants (13). The most common indications for retransplantation were cardiac allograft vasculopathy $(51 \%)$, primary or nonspecific graft failure (21\%), acute rejection $(9 \%)$, chronic rejection $(7 \%)$, hyperacute rejection $(3 \%)$ and other $(10 \%)$. Mean inter-transplant interval was $4.7 \pm 3.8$ years. As in adults, survival in retransplant recipients was inferior to that following primary transplantation (Figure 6, top panel), however, patients retransplanted greater than 6 months following transplant had better outcomes than when retransplantation occurred less than 6 months following primary transplant (Figure 6, bottom panel). If patients with primary graft failure less than 6 months following transplantation were excluded, survival following retransplantation did not differ from that following primary transplantation. 
Johnson et al.

Table 1: Single center series of heart retransplantation in adults

\begin{tabular}{|c|c|c|c|c|c|c|}
\hline Center & Era & $\begin{array}{l}\text { Retransplants } \\
\text { (N/\% Total } \\
\text { Transplants) }\end{array}$ & $\begin{array}{c}\text { Indications } \\
(\%)\end{array}$ & Interval & Survival & Comments \\
\hline Columbia (6) & 1992-2002 & $41 / 5.4 \%$ & $\begin{array}{l}\text { CAV 90\% } \\
\text { Rejection } 7 \% \\
\text { Nonspecific graft failure 2\% }\end{array}$ & $5.9 \pm 3.4 \mathrm{Yr}$ & $\begin{array}{l}1 \mathrm{Yr}-72 \% \\
3 \mathrm{Yr}-66 \% \\
5 \mathrm{Yr}-48 \% \\
7 \mathrm{Yr}-41 \%\end{array}$ & $\begin{array}{l}\text { Early mortality similar for } \\
\text { primary and retransplants }\end{array}$ \\
\hline $\begin{array}{l}\text { La Pitie } \\
\quad \text { Salpetriere (7) }\end{array}$ & 1973-1996 & $24 / 2.3 \%$ & $\begin{array}{l}\text { CAV } 46 \% \\
\text { Rejection } 29 \% \\
\text { Primary graft failure } 17 \% \\
\text { Other } 8 \%\end{array}$ & 1 day-11 Yr & $\begin{array}{l}1 \mathrm{Yr}-46 \% \\
5 \mathrm{Yr}-31 \%\end{array}$ & $\begin{array}{l}\text { If intertransplant interval }>1 \\
\text { Yr, } 1 \text { Yr survival } 62 \% \text { and } 4 \\
\text { Yr survival } 46 \%\end{array}$ \\
\hline Utah (8) & 1985-1991 & $20 / 4.8 \%$ & $\begin{array}{l}\text { CAV } 50 \% \\
\text { Rejection } 40 \% \\
\text { Nonspecific graft failure 10\% }\end{array}$ & NR & 1 Yr-48\% & $\begin{array}{l}\text { For patients surviving }>6 \\
\text { months after retransplant, } \\
\text { survival same as primary } \\
\text { transplants }\end{array}$ \\
\hline Vienna (9) & 1984-1999 & $31 / 4 \%$ & $\begin{array}{l}\text { CAV 35\% } \\
\text { Rejection 32\% } \\
\text { Primary graft failure 19\% } \\
\text { Other } 13 \%\end{array}$ & NR & $\begin{array}{l}1 \mathrm{Yr}-48 \% \\
3 \mathrm{Yr}-44 \% \\
5 \mathrm{Yr}-37 \%\end{array}$ & $\begin{array}{l}\text { Freedom from rejection } \\
\text { similar to primary } \\
\text { transplants }\end{array}$ \\
\hline Stanford (10) & 1968-1993 & $66 / 8 \%$ & $\begin{array}{l}\text { CAV } 56 \% \\
\text { Rejection } 26 \% \\
\text { Primary graft failure 14\% } \\
\text { Other } 5 \%\end{array}$ & NR & $\begin{array}{l}1 \mathrm{Yr}-55 \% \\
5 \mathrm{Yr}-33 \% \\
10 \mathrm{Yr}-22 \%\end{array}$ & $\begin{array}{l}\text { Patients with creatinine } \\
>2 \mathrm{mg} / \mathrm{dL} \text { had a high } \\
\text { probability of requiring } \\
\text { dialysis and death after } \\
\text { retransplantation }\end{array}$ \\
\hline
\end{tabular}

$\mathrm{CAV}=$ cardiac allograft vasculopathy; $\mathrm{NR}=$ not reported; $\mathrm{Yr}=$ year(s).

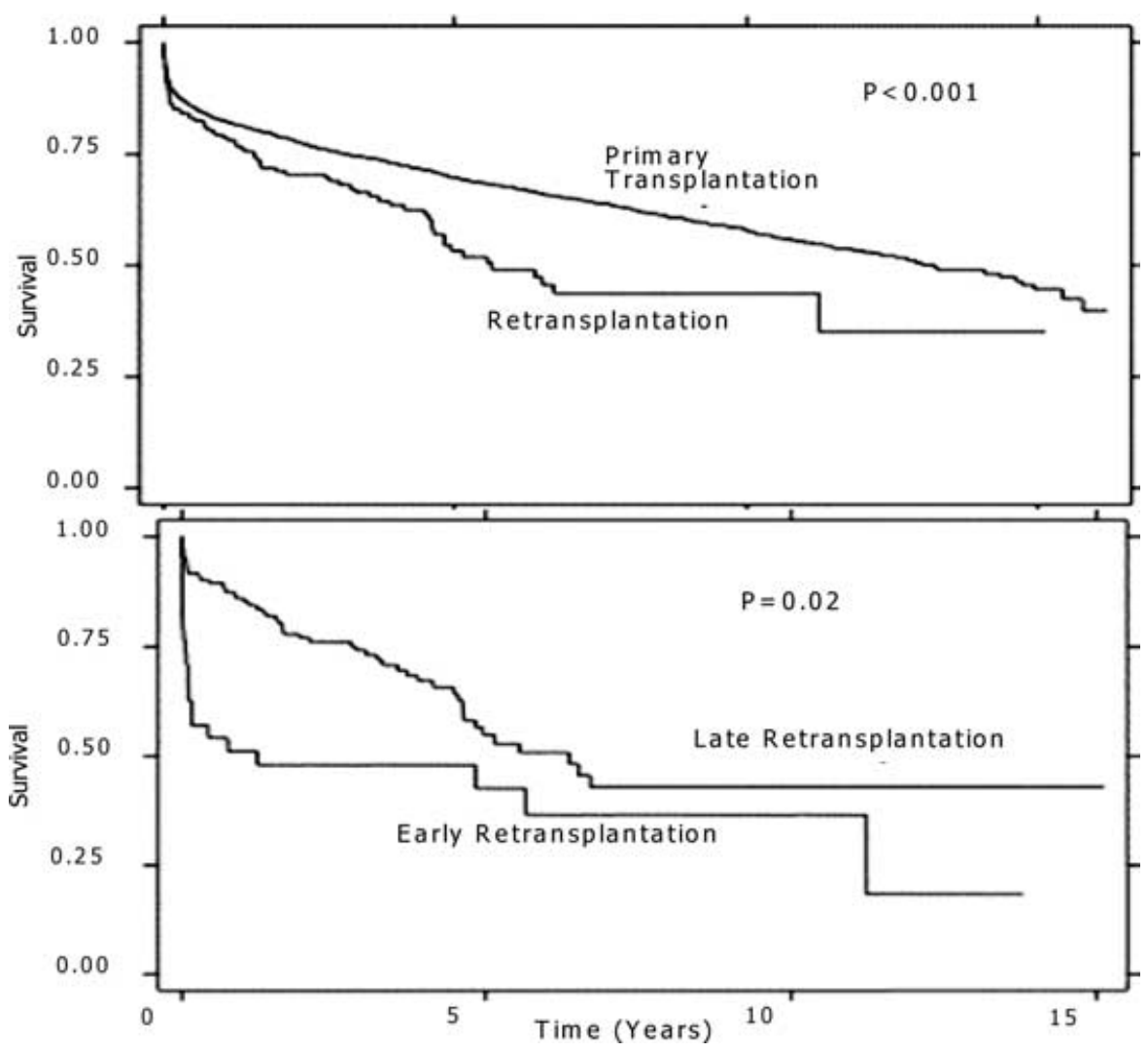

Figure 6: Survival following pediatric retransplantation compared with primary transplantation (top panel) and effect of intertransplant interval (Early $=$ $<6$ months, Late $=>6$ months) on outcome following pediatric retransplantation (bottom panel) in the United Network for Organ Sharing (UNOS) Database. (Reproduced with permission, J Thoracic Cardiovasc Surg 2005; 130(2):542-546.) 
Table 2: Single and multicenter series of pediatric heart retransplantation

\begin{tabular}{|c|c|c|c|c|c|c|}
\hline Center(s) & Era & $\begin{array}{l}\text { Retransplants } \\
\text { (N/\% Total } \\
\text { Transplants) }\end{array}$ & $\begin{array}{c}\text { Indications } \\
(\%)\end{array}$ & Interval & Survival & Comments \\
\hline Emory (16) & 1988-2003 & $20 / 13 \%$ & $\begin{array}{l}\text { CAV } 50 \% \\
\text { Rejection } 10 \% \\
\text { Chronic graft failure } 27 \% \\
\text { Acute graft failure } 10 \%\end{array}$ & $5.5 \pm 3.3 Y^{*}$ & $\begin{array}{l}30 d-95 \% \\
1 \text { Yr-94\% } \\
3 \text { Yr-78\% }\end{array}$ & $\begin{array}{l}\text { Survival similar to primary } \\
\text { transplants } \\
\text { Rejection similar to primary } \\
\text { transplants }\end{array}$ \\
\hline Loma Linda (17) & 1985-1999 & $22 / 6.3 \%$ & $\begin{array}{l}\text { CAV } 73 \% \\
\text { Rejection } 5 \% \\
\text { Primary graft failure 23\% }\end{array}$ & 7.2 Yr* & 3 Yr-82\% & $\begin{array}{l}\text { Survival similar to primary } \\
\text { transplants }\end{array}$ \\
\hline $\begin{array}{l}\text { Columbia, Stanford, } \\
\text { Childrens Hospital } \\
\text { of Pittsburgh, } \\
\text { Arizona (18) }\end{array}$ & 1974-1992 & $18 / \mathrm{NR}$ & $\begin{array}{l}\text { CAV } 65 \% \\
\text { Acute rejection } 24 \% \\
\text { Chronic rejection } 6 \% \\
\text { Primary graft failure } 6 \%\end{array}$ & $2 \mathrm{~d}-15.6 \mathrm{Yr}$ & $\begin{array}{l}1 Y r-71 \% \\
3 Y r-47 \%\end{array}$ & $\begin{array}{l}\text { Rejection and infection } \\
\text { similar to primary transplants } \\
\text { Survival better if > } 6 \text { month } \\
\text { inter-transplant interval }\end{array}$ \\
\hline
\end{tabular}

*Excluding early acute retransplantations for graft failure.

$\mathrm{CAV}=$ cardiac allograft vasculopathy; $\mathrm{d}=$ days; $\mathrm{NR}=$ not reported; $\mathrm{Yr}=$ year(s).

In an analysis of 224 pediatric heart retransplants in the ISHLT Registry, survival was $78 \%$ at 1 year, $73 \%$ at 3 years and $58 \%$ at 5 years (14). Retransplantation at less than 1 year of age or with an inter-transplant interval of less than 1 year was associated with inferior survival compared with primary transplantation. When this patient group was excluded, survival following retransplantation was not significantly different from that after primary transplant.

Chin et al. reported data on 59 pediatric heart retransplantations at 23 centers from 1993 through 2004 (15). The indications for retransplantation were cardiac allograft vasculopathy (46\%), graft failure (32\%) and acute rejection (14\%). Retransplant survival was $81 \%$ at 1 year, $69 \%$ at 3 years and $60 \%$ at 5 years. Retransplantation greater than 6 months following initial transplantation had a survival equal to primary transplantation. When retransplantation occurred less than 6 months following the primary transplant, 1-year survival was only $30 \%$. Rejection and infection were similar in primary versus retransplant recipients. However, infection was a more common cause of death in the retransplant group.

Table 2 summarizes data from selected series concerning pediatric heart retransplantation (16-18). The percentage of retransplants appears somewhat higher than in adults, however, the indications were similar. Survival was similar to primary transplant recipients, especially when an intertransplant interval greater than 6 months was present. No differences were seen in rejection and infection rates between retransplant and primary transplant recipients.

\section{Immunosupression Following Retransplantation}

Clinical series have not addressed the issue of what immunosuppression to use in retransplant recipients. Although it might be thought that more immunosuppression would be needed following retransplantation than primary transplant, the retransplant recipient is already immunosuppressed, and perhaps less rather than more immunosuppression may be adequate and even advisable to decrease the risk of infection and malignancy. Indeed, rejection following retransplantation is similar to that following primary transplant and some series report a higher incidence of infection following retransplantation. The working group recommends that the selection of the immunosuppressive protocol for retransplantation should take into consideration time from primary transplant, indication for retransplant, recipient age, prior rejection history, degree of HLA match between the recipient and the first and second donors, presence of preformed HLA antibodies, previous patient experience with immunosuppressive agents (toxicities, renal function), existing immunosuppressive complications (malignancy, infection, renal function, etc.), and advances in immunosuppressive agents and drug monitoring over time.

\section{Alternatives to Retransplantation}

As the most common indication for retransplantation is cardiac allograft vasculopathy, the clinician is frequently faced with a decision as to when a patient with cardiac allograft vasculopathy should be considered for retransplantation. The severity of allograft vasculopathy is important, as patients with severe allograft vasculopathy have a 1 -year survival of only $54 \%$ whereas patients with mild or moderate vasculopathy have a 1-year survival greater than $85 \%$, which would not appear to justify retransplantation (19). Revascularization by percutaneous coronary intervention (angioplasty or stenting) or coronary artery bypass grafting can be performed in patients with more focal disease, however, outcomes following revascularization are also sub-optimal, so defining when revascularization versus retransplantation should be performed requires further study. The use of sirolimus-eluting stents provides hope that restenosis following stenting for cardiac allograft 
vasculopathy may decrease, however, this has not been proven.

Oral sirolimus therapy appears to alter the natural history of cardiac allograft vasculopathy (20). Thus, most transplant centers are either substituting sirolimus for azathioprine or mycophenolate or adding sirolimus when allograft vasculopathy is diagnosed. However, the possibility of a positive effect on the course of vasculopathy must be balanced against the potential for increased renal dysfunction when sirolimus is used in conjunction with full dose calcineurin inhibitors. The role of pacemakers and implantable defibrillators in patients with allograft vasculopathy needs to be defined.

Immunosuppressive regimens using mycophenolate versus azathioprine (21) or using the target of rapamycin (TOR) inhibitors sirolimus (22) or everolimus (23) versus azathioprine delay the onset and progression of allograft vasculopathy. Statin therapy (specifically pravastatin and simvastatin) from the time of transplantation also decreases allograft vasculopathy $(24,25)$. Thus, modifications to the medication regimen at the time of transplantation may decrease the future need for retransplantation for cardiac allograft vasculopathy.

\section{Ethical Considerations in Heart Retransplantation}

An area that shouldn't be ignored when retransplantation is being considered is the ethics of retransplantation. Donor hearts are in limited supply. Therefore, is it appropriate to provide a second transplant to a previous transplant recipient when there remain deaths on the waiting list of patients who have not yet received a first transplant? On the other hand, what is the responsibility of the transplant team to a heart transplant recipient who has 'done everything right' and still requires retransplantation? The working group believes that whether considering primary transplant or retransplantation, an important factor in defining transplant candidacy is what the likelihood of success is following transplantation. Based on the selection criteria/considerations proposed here, it would appear that appropriate candidates for retransplantation could be defined. Indeed, carefully selected candidates for retransplantation may have a better chance at a successful outcome than some patients being considered for and undergoing primary transplantation today.

\section{Working Group on Heart Retransplantation Consensus}

Based upon available data and personal experience, the working group on Heart Retransplantation concludes that indications for heart retransplantation are: (i) Chronic severe cardiac allograft vasculopathy not amenable to medical or surgical therapy with

(a) symptoms of ischemia or heart failure (should be considered) and/or

(b) asymptomatic moderate to severe LV dysfunction (may be considered).

(ii) Chronic graft dysfunction with progressive heart failure in the absence of active rejection. Important considerations in retransplantation are:

(a) Patients with graft failure due to ongoing acute rejection with hemodynamic compromise, especially less than 6 months post-transplant, are inappropriate retransplant candidates.

(b) Patients requiring short-term mechanical cardiorespiratory support may not be good retransplant candidates and deserve careful consideration on an individual basis.

(c) The efficacy of retransplantation in older candidates (60-65 years) is not well established.

(d) The efficacy of retransplantation in the presence of post-transplant lymphoproliferative disorder (disease-free less than 2 years) is not established.

(e) Guidelines established for primary transplant candidates should be strictly followed in selecting candidates for retransplantation.

Areas in which further information is required to better understand the role of heart retransplantation include:

(i) The natural history of cardiac allograft vasculopathy using contemporary management strategies.

(ii) The immunologic differences among retransplants and between primary transplants and retransplants and how this affects response to immunosuppressants.

(iii) The number of unused donor hearts available for retransplantation, particularly pediatric retransplantation.

(iv) The impact of circulating antibodies on outcomes following retransplantation and on the need to desensitize retransplants candidates in whom they are found.

(v) The role of kidney transplant combined with heart retransplantation for retransplant candidates with significant renal insufficiency.

\section{Acknowledgments}

The authors wish to acknowledge the American Society of Transplantation, the American Society of Transplant Surgeons and the National Institute of Allergy and Infectious Diseases for their financial support of the Consensus Conference on Retransplantation.

\section{References}

1. Magee JC, Barr ML, Basadonna GP et al. Repeat organ transplantation in the United States, 1996-2005. Am J Transplant 2007; 7(Part 2): 1424-1433. 
2. Ensley RD, Hunt S, Taylor DO et al. Predictors of survival after repeat heart transplantation. J Heart Lung Transplant 1992; 11: S142-S158.

3. Taylor DO, Edwards LB, Boucek MM et al. Registry of the International Society for Heart and Lung Transplantation: Twenty-Second Official Adult Heart Transplant Report - 2005. J Heart Lung Transplant 2005; 24: 945-955.

4. Srivastava R, Keck BM, Bennett LE, Hosenpud JD. The results of cardiac retransplantation: An analysis of the Joint International Society for Heart and Lung Transplantation/United Network for Organ Sharing Thoracic Registry. Transplantation 2000; 70: 606612.

5. Radovancevic B, McGiffin DC, Kobashigawa JA et al. Retransplantation in 7,290 primary transplant patients: A 10-year multiinstitutional study. J Heart Lung Transplant 2003; 22: 862-868.

6. Topkara VK, Dang NC, John R et al. A decade experience of cardiac retransplantation in adult recipients. J Heart Lung Transplant 2005; 24: $1745-1750$.

7. Schnetzler B, Pavie A, Dorent R et al. Heart retransplantation: A 23-year single-center clinical experience. Ann Thorac Surg 1998; 65: 978-983.

8. Karwande SV, Ensley RD, Renlund DG et al. Cardiac retransplantation: A viable option? Ann Thorac Surg 1992; 54: 840-845.

9. Schlechta B, Kocher AA, Ehrlich $M$ et al. Heart retransplantation: Institutional results of a series of 31 cases. Transplant Proc 2001; 33: 2759-2761.

10. Smith JA, Ribakove GH, Hunt SA et al. Heart retransplantation: The 25-year experience at a single institution. J Heart Lung Transplant 1995; 14: 832-839.

11. John $R$, Chen JM, Weinberg A et al. Long-term survival after cardiac retransplantation: A twenty-year single-center experience. $J$ Thorac Cardiovasc Surg 1999; 117: 543-555.

12. Boucek MM, Edwards LB, Keck BM, Trulock EP, Taylor DO, Hertz MI. Registry of the International Society for Heart and Lung Transplantation: Eighth Official Pediatric Report - 2005. J Heart Lung Transplant 2005; 24: 968-982.

13. Mahle WT, Vincent RN, Kanter KR. Cardiac retransplantation in childhood: Analysis of data from the United Network for Organ Sharing. J Thorac Cardiovasc Surg 2005; 130: 542-546.
14. Almond CS, Blume ED, Edwards LB, Boucek MM. Risk factors for mortality following pediatric heart retransplantation: Analysis from the International Society of Heart and Lung Transplantation Registry (abstract). J Heart Lung Transplant 2006; 25: S51.

15. Chin C, Naftel D, Pahl E et al. Cardiac re-transplantation in pediatrics: A multi-institutional study. J Heart Lung Transplant 2006; 25: 1420-1424.

16. Kanter KR, Vincent RN, Berg AM, Mahle WT, Forbess JM, Kirshbom PM. Cardiac retransplantation in children. Ann Thorac Surg 2004; 78: 644-649.

17. Dearani JA, Razzouk AJ, Gundry SR et al. Pediatric cardiac retransplantation: Intermediate-term results. Ann Thorac Surg 2001; 71: 66-70.

18. Michler RE, Edwards NM, Hsu D et al. Pediatric retransplantation. J Heart Lung Transplant 1993; $12(6$ Pt 2): S319-S327.

19. Costanzo MR, Naftel DC, Pritzker MR et al. Heart transplant coronary artery disease detected by coronary angiography: A multiinstitutional study of preoperative donor and recipient risk factors. J Heart Lung Transplant 1998; 17: 744-753.

20. Mancini D, Pinney S, Burkhoff, D et al. Use of rapamycin slows progression of cardiac transplantation vasculopathy. Circulation 2003; 108: 48-53.

21. Eisen HJ, Kobashigawa J, Keogh $A$ et al. Three-year results of a randomized, double-blind, controlled trial of mycophenolate mofetil versus azathioprine in cardiac transplant recipients. J Heart Lung Transplant 2005; 24: 517-525.

22. Keogh A, Richardson M, Ruygrok $P$ et al. Sirolimus in de novo heart transplant recipients reduces acute rejection and prevents coronary artery disease at 2 years: A randomized clinical trial. Circulation 2004; 110: 2694-2700.

23. Eisen HJ, Tuzcu EM, Dorent $R$ et al. Everolimus for the prevention of allograft rejection and vasculopathy in cardiac-transplant recipients. N Engl J Med 2003; 349: 847-858.

24. Kobashigawa JA, Moriguchi JD, Laks $\mathrm{H}$ et al. Ten-year follow-up of a randomized trial of pravastatin in heart transplant patients. $J$ Heart Lung Transplant 2005; 24: 1736-1740.

25. Wenke K, Meiser B, Thiery J et al. Simvastatin initiated early after heart transplantation: 8-year prospective experience. Circulation 2003; 107: 93-97. 